\title{
Developing the Eastern Mediterranean Health Journal to support public health research in the Region
}

Phillip Dingwall ${ }^{1}$, Ahmed Mandil ${ }^{2}$ and Arash Rashidian ${ }^{3}$

\begin{abstract}
${ }^{1}$ Managing Editor, Eastern Mediterranean Health Journal, WHO Regional Office for the Eastern Mediterranean, Cairo, Egypt. ${ }^{2}$ Coordinator, Research, Development and Innovation, WHO Regional Office for the Eastern Mediterranean, Cairo, Egypt. ${ }^{3}$ Director, Department of Information, Evidence and Research, WHO Regional Office for the Eastern Mediterranean, Cairo, Egypt.
\end{abstract}

Citation: Dingwall P; Mandil A; Rashidian A. Developing the Eastern Mediterranean Health Journal to support public health research in the Region. East Mediterr Health J. 2018;24(12):1117-1118. https://doi.org/10.26719/2018.24.12.1117

Copyright (C) World Health Organization (WHO) 2018. Some rights reserved. This work is available under the CC BY-NC-SA 3.o IGO license (https:// creativecommons.org/licenses/by-nc-sa/3.o/igo).

Since 1995, the Eastern Mediterranean Health Journal (EMHJ) (1) has sought to publish public health research, regionally and globally, in accordance with the mandate and goals of the World Health Organization (WHO) $(2,3)$. As part of a family of WHO journals, the EMHJ is an open access public health journal and makes no charge for review or publication of accepted papers, allowing research manuscripts as well as policy-related works from institutions with different financial status an opportunity to be published and remain freely accessible to all. Supporting countries that are developing their health research base remains an important focus for the EMHJ, in line with the WHO Thirteenth General Programme of Work 2019-2023 (GPW13), and its mandate to strengthen research on public health priorities (4).

During 2018, a variety of developments for the EMHJ took place. The cover design and layout formats of the manuscripts were updated to improve visibility and attract further attention to the journal's content. Also, in line with standard academic publishing, all published articles are now allocated a digital object identifier (DOI), and this is being applied retroactively to all EMHJ issues since the journal's inception in 1995. This development - along with improved article classification in bibliographic databases and indexes - allows for greater visibility online and improved opportunities for citations of published research. Interested readers have also noted how EMHJ webpages have also improved substantially and have resulted in greater ease in locating new and older content in the journal. More importantly, we have now added an "in press" feature to the journal, with immediate DOI assignment, to speed up the availability of accepted material as well as their life cycle.

In addition, the EMHJ now falls under the Creative Commons license (5) agreement adopted by WHO Press across its journal titles, allowing for the use of extracts from published material without the laborious process of seeking copyright permissions, although still subject to strict citation requirements (5).

Maintaining the health research integrity of accepted papers has always remained a core focus of the EMHJ. Its review process (minimum two anonymous reviewers and statistical reviewer) and stages of editing (from language to technical) are rigorously enforced to achieve this standard. Manuscripts are reviewed in two stages: a preliminary rapid 'internal' review of received manuscript abstracts, followed by further assessment from external peer reviewers of those manuscripts considered to be of interest to the EMHJ audience. This approach has helped to increase the standard of accepted manuscripts in the EMHJ, to give the chance to authors of manuscripts that are beyond EMHJ interests to submit elsewhere, and to reduce the burden on our peer reviewers who generously provide their time for this purpose.

In order to support authors with the publication process, the journal regularly reviews its submissions criteria and its ethical guidelines for papers were updated in June 2015 (6) and are available on the journal's homepage. However, despite these developments the current backlog of already accepted articles still needs to be addressed and published in a timely manner, due primarily to a growing interest in the journal in light of its continuous development and thus an increasing number of submissions. The matter is of primary concern and procedures are already enacted to mitigate this deficiency.

Despite the broad nature of public health research, the EMHJ willingly produces a number of specialized issues focusing on specific areas of public health development and concern of relevance to the Region. These special thematic issues, usually one or two per year, bring together original research from a cross-section of scientists and health researchers operating in low and high-income countries, offering the focused insight and perspectives on regional issues that might not normally reach global attention. During 2018, the EMHJ published two special issues - "Scaling up action on the prevention and control of non-communicable diseases in the Eastern Mediterranean Region" (7) and "Scaling up health workforce in the Eastern Mediterranean" (8) - that received a substantial readership response, with the number of online hits for these issues now running in the thousands. Indeed, previous EMHJ special issues continue to garner great attention for their often unique published material, in particular the special issue on: "Substance Use in the Eastern Mediterranean Region" 
(9), which till date is receiving the greatest number of online hits, followed by special issues on influenza (10) and mental health (11).

While 2018 figures will be updated late in 2019, due to the processing time of some manuscripts that require different rounds of peer reviews, the status of 2017 submissions can provide the contemporary status of the journal's throughput. Altogether during 2017, 686 manuscripts were submitted to the EMHJ; $19 \%$ of the submissions were sent to peer review after initial assessments, with an overall acceptance rate of $9.5 \%$. Twenty of the 22 countries of the Eastern Mediterranean Region submitted manuscripts to EMHJ in 2018. The greatest number of submissions was received from the Islamic Republic of Iran, followed by Saudi Arabia, Egypt, Jordan and Pakistan, and a rising number of papers from Oman, Palestine, Turkey, and the United Arab Emirates. Although the EMHJ primarily focuses on the Region for its source of submissions, papers for consideration have also been received from public health researchers in Argentina, Australia, Canada, China, Croatia, Cyprus,
Denmark, France, Germany, Greece, India, Indonesia, Italy, Kazakhstan, Nigeria, Norway, Romania, South Korea, Switzerland, United Kingdom, United States of America, and Vietnam. In total, we published 73 research manuscripts, 4 short research communications, 2 letters to the editor, and 10 manuscripts in other categories during 2018, including the current issue. The most frequently viewed and downloaded manuscripts in 2017 were five publications that focused on substance use (1216).

The developments undertaken on the EMHJ during 2018 have born fruit, culminating in the recognition for "Best Journal 2018" by the Research Excellence Awards in Cairo, Egypt, 8 November 2018, and awarded by the Minister of Education and Technical Education, Egypt. Not one to rest on its laurels, the EMHJ is currently examining future improvements during 2019 to uphold its mandate of supporting public health research in the EMR and beyond, including new software applications and commissioning special issues on topics of particular relevance to the Eastern Mediterranean Region.

\section{References}

1. Eastern Mediterranean Health Journal homepage. Cairo: World Health Organization Regional Office for the Eastern Mediterranean Region; 2018 (http://www.emro.who.int/emh-journal/eastern-mediterranean-health-journal/home.html).

2. Mandil A, Curlet F, Nour El-Din H, Abu-Saleh N, Ahmed MA. Eastern Mediterranean Health Journal (EMHJ): a 20-year overview (1995-2014). East Mediterr Health J. 2016;22(8):628-637. https://doi.org/10.26719/2016.22.8.628.

3. Alwan A. From the Editor-in-Chief: Filling the gap: restoring EMHJ's public health identity. East Mediterr Health J. 2016;20(6):359. https://doi.org/10.26719/2014.20.6.359.

4. World Health Organization. 13th general programme of work (GPW13) WHO impact framework. Geneva: World Health Organization; 2018 (https://www.who.int/about/what-we-do/GPW13_WIF_White-Paper_English.pdf?ua=1).

5. Creative Commons. About the licenses. Mountain View, CA: Creative Commons; 2017 (https://creativecommons.org/licenses/).

6. Eastern Mediterranean Health Journal. Guidelines for authors. Cairo: World Health Organization Regional Office for the Eastern Mediterranean; 2015 (http://www.emro.who.int/emh-journal/authors/emhj-guidelines-on-ethical-conduct-and-publication-of-health-research.html).

7. Fikri M, Hammerich A. Scaling up action on the prevention and control of noncommunicable diseases in the WHO Eastern Mediterranean Region. East Mediterr Health J. 2018;24(1):3-4. https://doi.org/10.26719/2018.24.1.3.

8. Gedik FG, Buchan J, Mirza Z, Rashidian A, Siddiqi S, Dussault G. The need for research evidence to meet health workforce challenges in the Eastern Mediterranean Region. East Mediterr Health J. 2018;24(9):811-812. https://doi.org/10.26719/2018.24.9.811.

9. Saeed K, Taj M. A regional framework for action on substance use and public health. East Mediterr Health J. 2017;23(3):129-130. https://doi.org/10.26719/2017.23.3.129.

10. Malik M, Mahjour J, Khan W, Alwan A. Influenza in the Eastern Mediterranean Region: identifying the unknowns for detection and control of epidemic and pandemic threats. East Mediterr Health J. 2016;22(7):428-429. https://doi.org/10.26719/2016.22.7.428.

11. Alwan A, Saeed K. A new agenda for mental health in the Eastern Mediterranean Region. East Mediterr Health J. 2015;21(7):459460. https://doi.org/10.26719/2015.22.7.459.

12. Odenwald M, al'Absi M. Khat use and related addiction, mental health and physical disorders: the need to address a growing risk. East Mediterr Health J. 2017;23(3):236-244. https://doi.org/10.26719/2017.23.3.236.

13. Batool S, Manzoor I, Hassnain S, Bajwa A, Abbas M, Mahmood M, et al. Pattern of addiction and its relapse among habitual drug abusers in Lahore, Pakistan. East Mediterr Health J. 2017;23(3):168-172. https://doi.org/10.26719/2017.23.3.168.

14. Clark N, Dolan K, Farabee D. Public health alternatives to incarceration for drug offenders. East Mediterr Health J. 2017;23(3):222230. https://doi.org/10.26719/2017.23.3.222.

15. Amin-Esmaeili M, Hefazi M, Radgoodarzi R, Motevalian A, Sharifi V, Hajebi A, et al. Out-of-pocket cost of drug abuse consequences: results from Iranian National Mental Health Survey. East Mediterr Health J. 2017;23(3):150-160. https://doi. org/10.26719/2017.23.3.150.

16. Renstrom M, Ferri M, Mandil A. Substance use prevention: evidence-based intervention. East Mediterr Health J. 2017;23(3):198205. https://doi.org/10.26719/2017.23.3.198. 